Therefore, as a sole source of information, they are not and should not be equated to proof of medical malpractice. While a newspaper may publish Dr Gulhati's article without references, that would be inappropriate in an academic journal such as the Indian Journal of Medical Ethics, which must insist on appropriate scientific references in all articles accepted for publication. If the Indian Journal of Medical Ethics publishes an article alleging serious malpractice based exclusively on newspaper reports, then it would be guilty of editorial malpractice.

What we lack in India is a credible mechanism for airing complaints or serious misgivings by well-intentioned outsiders about a particular research trial. In the USA, at the public hospital where I practised for 30 years, if any member of the public had serious doubts about a trial conducted in the hospital, he/she could approach a lay member of the hospital's Institutional Review Board (IRB). The details of the complaint were discussed by the IRB and, when indicated, an independent reviewer was appointed to investigate such charges. The findings were made public in a timely manner. I do not know if such mechanisms exist in India. If not, these are critically needed and would protect researchers from baseless charges.

Research is a vital necessity for India. While we must protect people from unscrupulous or fraudulent research trials, we must not discourage research by painting most researchers with a tarred brush.

Bashir Mamdani

\section{Clinical trials: in the crossfire}

Dr Gulhati has lamented about the unscrupulous methods adopted while conducting clinical trials and has called for strengthening regulatory authorities. While we appreciate the spirit of the article, we are sorry to note that Shantha Biotechnics has unnecessarily been mentioned in the opening paragraph. Now it is public knowledge that a tussle between two government agencies has dragged us into the controversy. Several articles are still appearing in Bio Spectrum, Business World, etc. questioning the GEAC's stand in this case. How can a committee, formed to monitor environmental issues supervise and evaluate clinical trials?

We have not passed on the buck as alleged in the article. As per the new guidelines, the DCGI alone is competent to clear clinical trials and we have approached them. If GEAC has not updated its records, we cannot help the situation. Further, the GEAC has relied too much upon a Bangalore-based NGO's false allegations such as trials being shifted to Bangalore in view of deaths, the volunteers not being insured, etc. Since the NGO inflated the number of deaths from two to eight and tried to blackmail us, we have filed a suit against them. It is unfortunate that Dr Gulhati did not crosscheck with us before writing the article.

Does Dr Gulhati sincerely believe that there would not have been any deaths during clinical trials had we obtained clearance from the GEAC? In any trial, volunteers are chosen at different stages of the disease to test the efficacy and safety of the drug. It is but natural for some of them to succumb during the trial. In the case of r-streptokinase comparative double-blind trials, out of 96 patients administered Shankinase (our r-streptokinase) three died (mortality rate $3.1 \%$ ) and out of the 54 administered Streptase (comparative drug) another three died (mortality rate $5.5 \%$ ). The Indian Heart Journal, in its latest issue states that the normal range is $8 \%-12.5 \%$. The DCGI informed GEAC that the accepted range is $6 \%$ (Economic Times; March 12, 2003).

Shantha Biotechnics values life highly and carries the logo 'Inspired by life'. Our motto is to make world-class health care products at an affordable cost to improve the quality of life. Shankinase is our third product. Both our earlier products won prestigious DSIR and National Technology Awards individually. Anyone can look at our track record to see how we suffered while conducting interferon alpha trials on monkeys. We agree with Dr Gulhati that clinical trials have to be monitored closely to see that unethical practices are not allowed. But tagging our name along with violators is most painful and regrettable. We are ready to share further information with the author.

MBS Prasad, Manager, Corporate Communications, Shantha Biotechnics Pvt Ltd, 3rd Floor, Serene Chambers, Road No.7, Banjara Hills, Hyderabad 500 034, India. e-mail: varaprasad@ shanthabiotech.com

\section{The author defends}

With regard to reference to Shantha Biotechnics, I wrote the following:

'How many people know that eight patients in Hyderabad who were administered recombinant streptokinase to test its efficacy and safety have died? According to the Genetic Engineering Approval Committee (GEAC), the trial was being conducted by the drug's manufacturer Shantha Biotechnics without taking clearance. Not surprisingly, the Company denies the allegation claiming that it had taken permission from the DCGI. In this game of passing the buck, no one is shedding any tears on the lives lost or compensating the families of those whose loved ones have died. Without any independent enquiry, the death of 'trial subjects', as they are impersonally called, has been attributed to 'causes other than the use' of the drug!'

In his rejoinder, Mr Prasad has not disputed any point except the number of reported deaths. I made the following 